\title{
CORNEAL VASCULARIZATION AFTER CATARACT EXTRACTION BY ZONULYSIS*
}

\author{
BY \\ D. W. HILL \\ St. Bartholomew's Hospital, London
}

CATARACT extraction, after the zonule has been dissolved by the action of the enzyme alpha-chymotrypsin, is a new procedure of great potential value. The parenteral use of this enzyme to reduce inflammatory reaction and assist the absorption of haematomata has been described (Fullgrabe, 1957). The application to cataract surgery is the result of work by Barraquer on the local effects of the enzyme injected into the eye. Several published papers (Barraquer, 1958a; Remky, 1958; Walser, 1958) indicate good results from extensive clinical trials; no specific post-operative complications are recorded. This case is presented because of the practical and theoretical interest of the complication encountered.

\section{Case Report}

A male aged 31 was referred by his refractionist to the hospital in February, 1953.

Examination.-He had well marked retinitis pigmentosa with early cataracts. The visual acuity was $6 / 24$ in the right eye with $-5 \mathrm{D}$ sph., $-4 \mathrm{D}$ cyl., axis $20^{\circ}$, and $6 / 36$ in the left with $-9 \mathrm{D}$ sph., $-0.5 \mathrm{D}$ cyl., axis $180^{\circ}$.

He attended at intervals, until in November, 1957, his best vision was $3 / 60$ right and left, and it was decided to perform a left cataract extraction. He had poorly reacting irregular pupils with some iris atrophy but no synechiae, and posterior cortical lens opacities in the axial regions.

Operation.-On January 22, 1958, a left intracapsular cataract extraction was performed (by D. W. H.) under local anaesthesia; the zonule was tough, but the cataract was removed with capsule apparently intact.

Operative Details.-Retrobulbar and instillation anaesthesia, facial nerve block, pre-placed McLean corneo-scleral suture, von Graefe's knife section, peripheral iridectomy, extraction by "tumbling" with Castroviejo's cross-action forceps and Arruga's expressor, wound toilet, conjunctival sutures.

Result.-At first dressing the anterior chamber was re-formed though shallow; a small hyphaema cleared rapidly. The patient was discharged on the 13th post-operative day; atropine and cortisone drops were prescribed. A fortnight later the left eye was quiet, and the corrected visual acuity was 6/18; the section was healed, but the iris was adherent to it between the 9 and 11 o'clock meridians; the pupil was oval and stuck to a thin glass membrane separating the vitreous from the anterior chamber. 
Second Operation.-On March 14, 1958, a left capsulotomy was performed (by D. W. H.) with a Ziegler's needle, and the glass membrane divided easily. There was no reaction, and 4 days later the visual acuity was $6 / 9$ ptly with $+9 \mathrm{D}$ sph., $+1 \mathrm{D}$ cyl., axis $10^{\circ}$.

Encouraged by the result of the operation to the left eye, a right cataract extraction was planned. Alpha-chymotrypsin was then available, and the case was judged to be suitable on account of age and the difficulty of the previous operation.

Third Operation.-On September 10, 1958, a right intracapsular cataract extraction was performed (D. W. H.) by zonulysis under local anaesthesia; the lens was extracted without difficulty.

Operative Details.-The technique was identical to that of the previous operation except for the actual extraction. After the peripheral iridectomy alpha-chymotrypsin was injected through the iridectomy and under the iris at 6 o'clock, between 0.25 and $0.5 \mathrm{ml}$. being used of a freshly made $1: 5,000$ solution, prepared from dried enzyme supplied for ophthalmic use. 3 to 4 minutes later the anterior chamber was irrigated with about $0.5 \mathrm{ml}$. Ringer's solution contained in a separate syringe. The lens was grasped above with Arruga's forceps and slid out easily. Pilocarpine was instilled.

Result.-At first dressing, after 48 hours, there was a marked reaction with lacrimation and corneal oedema; the anterior chamber was deep. The reaction settled steadily, and on the 14th post-operative day the eye appeared to be progressing satisfactorily. The patient was discharged on the 16th post-operative day; cortisone drops were prescribed.

On October 10, 1958 (a month post-operatively), the eye was still sensitive to light, though the anterior chamber was quiet. The section was healed, but the iris was adherent in two places. Slit-lamp examination revealed fine deep new vessels growing into the cornea from the whole of the cataract section; they had advanced about 2 to $3 \mathrm{~mm}$. on the temporal side, and rather more on the nasal side. Oculent. Hydrocortison. (B.N.F.) was prescribed, which the patient has continued to use three or four times a day up to the time of writing.

On October 31, 1958, the vessels showed little change apart from an advance on the nasal side where they had turned downwards below the horizontal meridian. The visual acuity was $6 / 12$ with $+9 \cdot 5 \mathrm{D}$ sph.

On November 21,1958 , the temporal vessels had advanced, the nasal were stationary, and those above were beginning to regress; a careful assessment of the plane of the vessels showed them to lie deep in the substantia propria in front of Descemet's membrane.

On December 12, 1958, 3 months after the operation, the condition of both eyes was reviewed. The corrected visual acuity in each eye was $6 / 9$, both eyes being white and quiet, sections well healed, tension normal, fundus appearances of advanced retinitis pigmentosa, and grossly contracted peripheral fields.

The left eye (first extraction) showed an anterior synechia between the iris and section occupying the arc 9 to 11 o'clock; there was no corneal vascularization.

The right eye showed a thick anterior synechia on the nasal side at 2 o'clock, and a temporal synechia between 10.30 and 11.30 o'clock; gonioscopy confirmed these findings, and revealed an additional diaphanous synechia, arising from the iris behind the iridectomy, and occupying the arc 12.30 to 1.30 o'clock. Many deep vessels, visible only on slit-lamp examination, were seen to have invaded the cornea from the cataract section (Figure, opposite); those above were empty, but circulation of blood could be detected in the nasal and temporal groups. The cornea was of normal thickness, and there were no opacities nor oedema.

\section{Discussion}

The factors responsible for corneal vascularization were reviewed by D. G. Cogan $(1948,1949)$, who advanced the theory that the immediate cause was corneal oedema, which reduced the mechanical barrier to the 


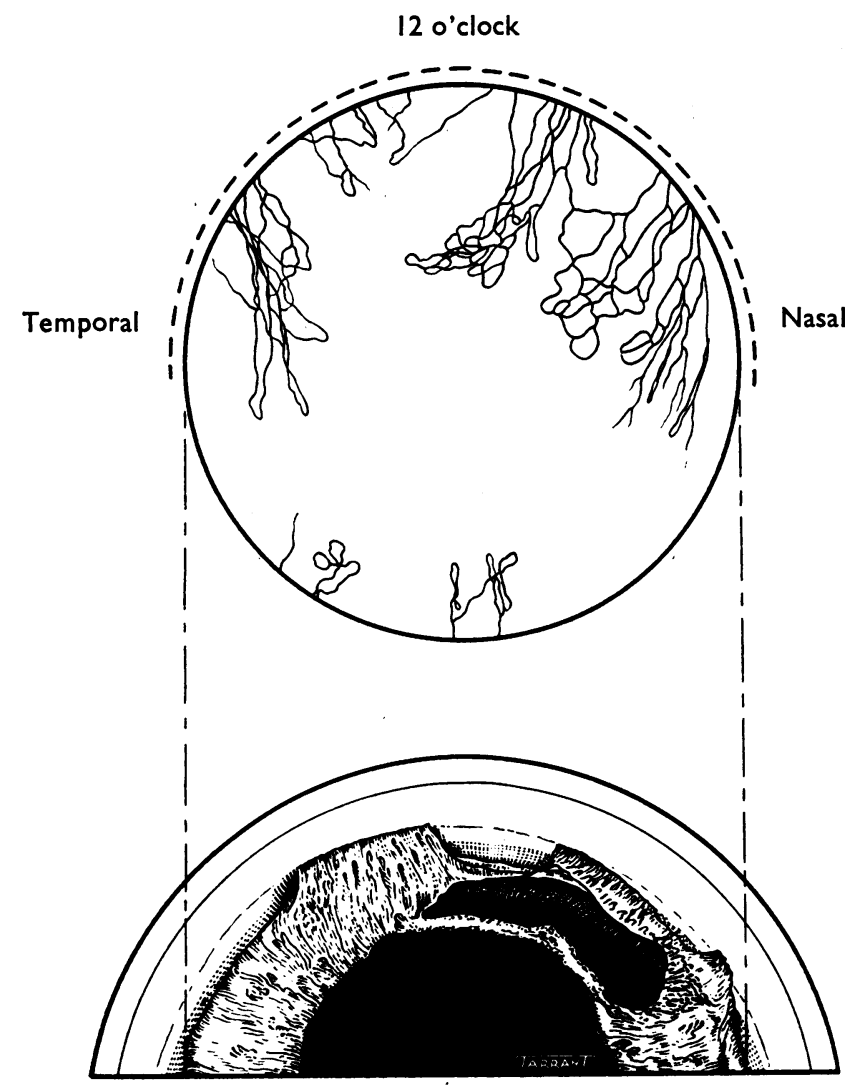

Figure.-Extent of corneal vascularization and its relation to iris synechiae on December 31, 1958.

The upper part, a diagram of the cornea, is projected upon a transposed gonioscopic view below, so that the nasal and temporal sides of the two parts of the Figure correspond.

penetration of vessels by opening the spaces between the corneal lamellae; he drew attention to the fact that vascularization occurs only when the oedema has reached the limbus at some point, thus emphasizing the mechanical nature of the process. Meyer and Chaffee (1940), investigating the barrier to vascularization in the normal cornea, demonstrated the presence of a hyaluronic acid ester in the corneae of cattle; injections of a preparation of hyaluronidase into the cornea produced vascularization, which was prevented if the enzyme was first inactivated.

Alpha-chymotrypsin is a proteolytic enzyme, extracted commercially from bovine pancreas; though similar to trypsin it attacks different peptide linkages. Previously reported experimental and post-operative studies suggest that within the anterior segment of the eye it acts specifically upon the zonule, a specificity difficult to reconcile with its natural function as a 
pancreatic digestive enzyme. Possibly the fibres of the zonule are more susceptible than other ocular structures on account of the relatively high ratio of their surface area to volume, permitting more rapid enzyme action.

In the case reported in this paper, the sequence of events, a marked reaction with corneal oedema maximal at first dressing and then subsiding, indicates that some factor at operation was responsible. This type of postoperative reaction is often associated with prolonged or rough intra-ocular manipulation, but in these cases corneal vascularization is not usual. If enzymatic digestion of the tissues of the cornea had occurred, then on the basis of D. G. Cogan's theory vascularization might be expected, especially as vessels would have been presented to the cut edge of the cornea by the adherent iris. That the iris synechiae were of themselves insufficient to cause vascularization, is clearly demonstrated by the fortuitous control experiment afforded by the previous cataract extraction on the other (left) eye. This extraction also demonstrated that the basic operative technique could not be blamed for the vascularization.

An attack on the cornea by the enzyme might have been due either to faulty technique or to lack of purity of the enzyme preparation. J. E. H. Cogan (1958) advises injecting $0.25 \mathrm{ml}$. of the enzyme, rather less than was used in this case; however, the amount used by Barraquer (1958b) is not reported, and the communication does not suggest that it is critical. The technique adopted by Walser (1958) also differs from that of J. E. H. Cogan. The preparation of alpha-chymotrypsin used in this case was not of the brand used by Barraquer, but the manufacturers claim it to be of similar purity and efficacy; they discount the possibility of its containing any hyaluronidase, which is known to attack the corneal ground substance (Meyer and Chaffee, 1940). Newell (1958), commenting on Barraquer's communication, warns of the possible contamination of the enzyme with trypsin, which would have a deleterious effect on the eye. J. E. H. Cogan (1958), in common with the continental authors, advises multiple postplaced (i.e. after the cataract section) corneo-scleral sutures, presumably to ensure firm wound closure; this practice which is routine in some continental clinics has its own complications and would not seem to be essential to the technique of zonulysis if, as is claimed, the enzyme attacks the zonule only; it should be sufficient to close the wound by the method which the operator finds satisfactory in his routine intracapsular extractions.

The experience of this case suggests that alpha-chymotrypsin occasionally attacks the cornea, with consequent vascularization to which iris synechiae may contribute. It appears unlikely that there will be any serious interference with visual acuity in this case, but it is too early to pass a final judgement on this point. It might be wise to modify the operative technique, using the minimum quantity of enzyme and washing out the anterior chamber more thoroughly: careful wound closure is also necessary to avoid the risk of iris synechiae. 


\section{Summary}

(1) A case of corneal vascularization following cataract extraction by zonulysis is described. The other eye which had had a routine intra-capsular extraction served as a control.

(2) The mechanism of corneal vascularization and its relation to enzymatic zonulysis in this case is discussed.

(3) Steps to minimize the risk of this complication are suggested.

I wish to thank Mr. H. B. Stallard, under whose care the patient has been treated, for permission to operate and to publish this case, and for his advice and encouragement at all stages.

\section{REFERENCES}

Barraquer, J. (1958a). Klin. Mbl. Augenheilk., 133, 609. (1958b). Surv. Ophthal., 3, 299.

CoGAN, D. G. (1948). Trans. Amer. ophthal. Soc., 46, 457.

(1949). Arch. Ophthal. (Chicago), 41, 406.'

CogaN, J. E. H. (1958). Proc. roy. Soc. Med., 51, 927.

FullgRaBe, E. A. (1957). Ann. N.Y. Acad. Sci., 68, art. 1, p. 192.

MeYER, K., and ChAFFEE, E. (1940). Amer. J. Ophthal., 23, 1320.

NEWELL, F. W. (1958). Discussion of communication by Barraquer (1958b), p. 302.

REMKY, H. (1958). Klin. Mbl. Augenheilk., 133, 616.

WALSER, E. (1958). Ibid., 133, 619. 